\title{
$\mathrm{PH} 94_{\text {perspectivas }}$
}

a debate El marco legal para la protección del patrimonio paleontológico. ¿Qué pasa en tu comunidad?

| coordina Eloísa Bernáldez Sánchez

\section{Patrimonio paleontológico en áreas naturales protegidas: el caso del ANP municipal Paso Córdoba (provincia de Río Negro, Patagonia, Argentina)}

Leonardo Salgado, Ignacio Díaz-Martínez | Instituto de Investigación en Paleobiología y Geología. UNRN-CONICET (Argentina) URL de la contribución <www.iaph.es/revistaph/index.php/revistaph/article/view/4178>

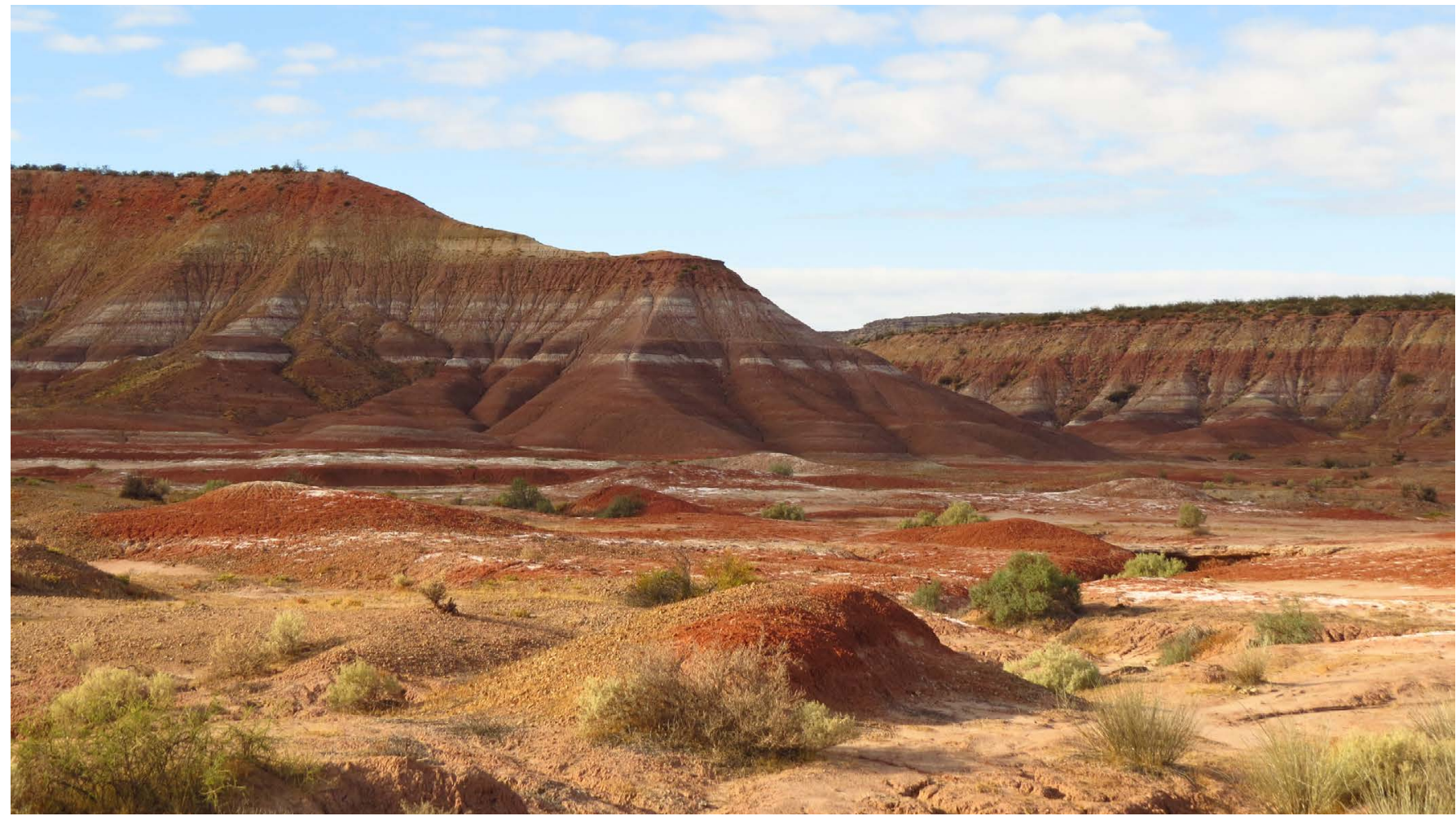

Valle de la Luna Rojo, Cretácico (ANP Paso Córdoba) | foto Ariel Méndez

Argentina posee más de 560 áreas naturales protegidas (nacionales, provinciales y municipales), con diferentes objetivos de conservación, algunas de importancia paleontológica. Como ejemplo de ese último tipo de áreas destaca el parque provincial de Ischigualasto, en la provincia de San Juan, en el noroeste argentino, con importantes yacimientos del Triásico continental.

En la provincia de Río Negro, en el norte de la Patagonia, existen algunas áreas naturales protegidas (ANP) pro- vinciales de importancia geológica y paleontológica: ANP Valle Cretácico (creado por ley provincial 3033/96), Monumento Natural El Anfiteatro (ubicado dentro del ANP Valle Cretácico, y creado por ley 4005/05), Monumento Natural Bosque de Troncos Petrificados (también dentro del ANP Valle Cretácico, y creado por el 4006/05) y el Monumento Natural Bosque Petrificado (ubicado en la llamada "Línea Sur" rionegrina, en la ciudad de Valcheta, creado por ley 3689/02). Como ejemplo de ANP geológica y paleontológica municipal tenemos el ANP Paso 
a debate El marco legal para la protección del patrimonio paleontológico. ¿Qué pasa en tu comunidad?

Córdoba, perteneciente a la municipalidad de General Roca.

El ANP Paso Córdoba, creada por ordenanza 2583 de septiembre de 1997, posee unas 17.000 ha de superficie. Allí afloran sedimentos del Cretácico Superior y del Mioceno-Plioceno. El área posee varios puntos de especial interés geológico y paleontológico, entre ellos, los llamados valles de la luna Rojo (Cretácico) y Amarillo (Mio-Plioceno). Originalmente, el objeto de conservación era el ambiente natural (art. 1 de la ordenanza 2583). Sin embargo, con el correr de los años, y a raíz de las investigaciones paleontológicas llevadas a cabo por distintos grupos de investigación, lo paleontológico fue tomando un mayor relieve entre los objetivos de conservación del área, al punto de ocupar un lugar central en la actualización del plan de manejo que la municipalidad se encuentra realizando. Entre los bienes inmuebles de valor paleontológicos existentes en el área se cuentan numerosos sitios con huellas de dinosaurios (algunos de ellos acondicionados para la visita), y otros con restos óseos, tanto de dinosaurios y tortugas cretácicas, como de mamíferos y tortugas miocenas.

La provincia de Río Negro cuenta con una ley de protección del patrimonio arqueológico y paleontológico (la 3041, sancionada en 1996) mientras que, a nivel nacional, existe otra ley, la 25743/03, que es aplicada sólo en áreas de jurisdicción nacional. La municipalidad de General Roca no posee una normativa específica para la protección del patrimonio paleontológico, sino una Dirección de Medio Ambiente que, en el día a día, se encarga del cuidado de los fósiles como parte del patrimonio natural del área. Como paleontólogos universitarios las autorizaciones para realizar nuestras campañas las solicitamos al gobierno de la provincia de Río Negro (la Secretaría de Cultura provincial es la autoridad de aplicación de la ley 3041), aunque debemos contar con el aval de la municipalidad, a pesar de pertenecer a la administración nacional.

Todos los integrantes de nuestro equipo de investigación son docentes de las licenciaturas de geología y paleon- tología de la Universidad Nacional de Río Negro, en la ciudad de General Roca. En varias asignaturas las prácticas se realizan en el ANP Paso Córdoba. Este hecho es, creemos, muy positivo, ya que favorece la toma de consciencia por parte de los alumnos sobre la necesidad de conservar no solo el material paleontológico en forma aislada, sino al sistema natural en su conjunto, al fósil y al entorno en el que se halla. En definitiva, los materiales paleontológicos como parte sustancial del ambiente natural que tutela la ordenanza municipal de creación del área. Parte de ese ambiente, además, se halla constituido por rasgos geológicos que dan cuenta de la historia natural de la región (estructuras tectónicas, estructuras sedimentarias, diferentes tipos de rocas, etc.). En lo formal, estos rasgos o estructuras geológicas no se encuentran protegidos por una norma específica, y en la práctica son resguardados por las normativas ambientales vigentes, tanto provincial como municipal.

Nos parece que la formación profesional del paleontólogo, al menos en Argentina, carece de esta visión integral que considera al bien fósil como parte del patrimonio natural y cultural de la sociedad. Entendemos que la protección del patrimonio paleontológico no puede separarse de la protección del medioambiente en general:

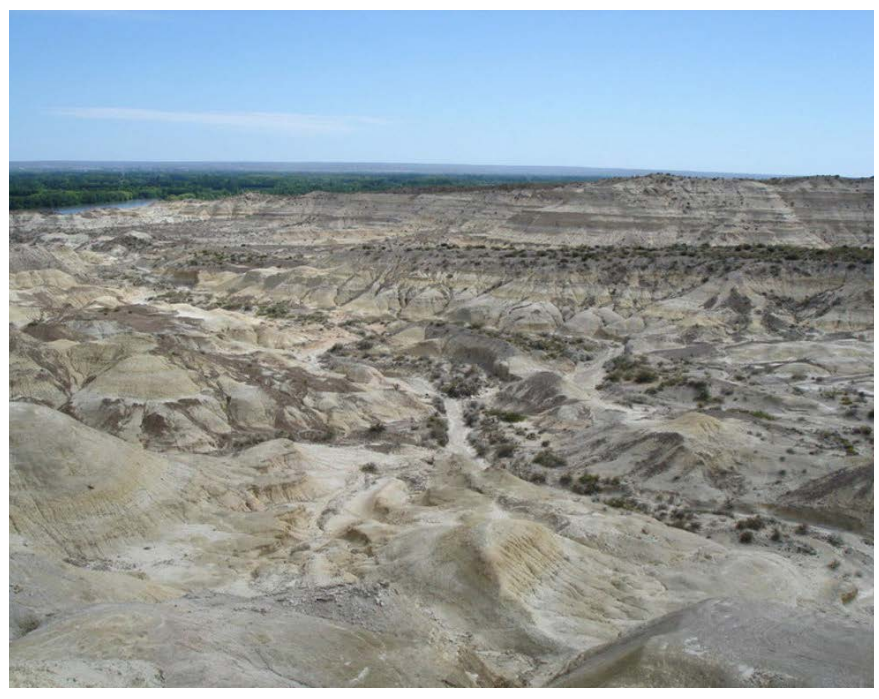

Valle de la Luna Amarillo, Mioceno (ANP Paso Córdoba) | foto Ariel Méndez 
a debate El marco legal para la protección del patrimonio paleontológico. ¿Qué pasa en tu comunidad?

esa es la visión que anima nuestras investigaciones y actuaciones hacia la comunidad.

Coincidimos en que es necesaria una ley específica para el resguardo del patrimonio paleontológico, ya que nuestra disciplina posee especificidades muy distintas a las de otras. Por ejemplo, en arqueología hay aspectos que no tienen su correlato en el ámbito paleontológico, como la delicada cuestión del vínculo que guardan los objetos y sitios arqueológicos con los pobladores originarios que habitan actualmente esos territorios.

Como profesionales hemos participado en la elaboración de las leyes de patrimonio paleontológico, la nacional y las provinciales. Menos injerencia hemos tenido en los proyectos de leyes medioambientales. De hecho, al menos desde nuestra experiencia, hubo históricamente en la provincia de Río Negro muy poca articulación entre las áreas de Cultura y Medioambiente. Esta desarticulación, en ocasiones directamente una total falta de comunicación, no ha sido positiva para la seguridad de los bienes patrimoniales paleontológicos.

Un elemento central en la preservación del patrimonio paleontológico son los museos. En Río Negro, los museos, provinciales y municipales, han cumplido un rol fundamental en el resguardo del patrimonio paleontológico, sobre todo en tiempos de estrecheces y recortes presupuestarios. Corresponde cerrar esta participación con un reconocimiento especial a todos los que trabajan en esas instituciones.

\section{BIBLIOGRAFÍA}

- LEY Nacional 25.743/03 de Protección del Patrimonio Arqueológico y Paleontológico. Boletín Oficial de la República Argentina [en línea], n. ${ }^{\circ} 30179,26$ de junio de 2003, pp. 1-3 <https://www.boletinoficial.gob. ar/\#!DetalleNormaBusquedaAvanzada/7254059/20030626> [Consulta: 24/04/2018]

- LEY Provincial 2184/97 de Protección y conservación del Patrimonio Histórico, Arqueológico y Paleontológico de la Provincia del Neuquén. Boletín Oficial [en línea], n. ${ }^{\circ} 2481$,
19/9/1997<https://www.legislaturaneuquen.gob.ar/CONSULTA Sanciones.aspx> [Consulta: 24/04/2018]

- LEY Provincial 3041/96 de Protección del Patrimonio Arqueológico y Paleontológico de la Provincia de Río Negro. Boletín Oficial de la Provincia de Rio Negro [en línea], $\mathrm{n} .{ }^{\circ}$ 3412, 31 de octubre de 1996, p. 2 <http://www.rionegro.gov.ar/ download/boletin/3412.PDF> [Consulta: 24/04/2018]

- LEY Provincial 3033/96 de creación del ANP Valle Cretácico. Boletín Oficial de la Provincia de Rio Negro [en línea], n. ${ }^{\circ}$ 3411, 28 de octubre de 1996, p. 1 <http://www.rionegro.gov.ar/ download/boletin/3411.PDF> [Consulta: 24/04/2018]

- LEY Provincial 3689/02 de creación del ANP Monumento Natural Bosque Petrificado. Boletín Oficial de la Provincia de Rio Negro [en línea], n. ${ }^{\circ}$ 4039, 24 de octubre de 2002, p. 1 <http://www.rionegro.gov.ar/download/boletin/4039.PDF> [Con sulta: 24/04/2018]

- LEY Provincial 4005/05 de creación del ANP Monumento Natural El Anfiteatro. Boletín Oficial de la Provincia de Rio Negro [en línea], n. ${ }^{\circ} 4373,2$ de enero de 2006, p. 3 <http://www. rionegro.gov.ar/download/boletin/4373.pdf> [Consulta: 24/04/ 2018]

- LEY Provincial 4006/05 de creación del ANP Monumento Natural Bosque de Troncos Petrificados. Boletín Oficial de la Provincia de Rio Negro [en línea], n. ${ }^{\circ} 4373,2$ de enero de 2006, p. 3. <http://www.rionegro.gov.ar/download/boletin/4373.pdf> [Consulta: 24/04/2018]

- ORDENANZA Municipal de General Roca 2583/97 de creación del ANP Paso Córdoba [en línea] Aprobada el 9 de setiembre de 1997 en Sesión Ordinaria n. 230 <https://www. generalroca.gov.ar/DigestoWeb/ABM/Consultas/ExportarPDF. aspx?|d=1751\&tipo=html> [Consulta: 24/04/2018] 